\title{
Experimental Study of Porosity Changes in Shale Caprocks Exposed to Carbon Dioxide-Saturated Brine II: Insights from Aqueous Geochemistry
}

\author{
Quin R.S. Miller, ${ }^{1}$ Xiuyu Wang, ${ }^{1, \dagger}$ John P. Kaszuba, ${ }^{1,2, *}$ Katherine M. Mouzakis, ${ }^{3, *}$ Alexis K. Navarre-Sitchler, \\ Vladimir Alvarado, John E. McCray, Gernot Rother, José Leobardo Bañuelos, ${ }^{6, \S}$ and Jason E. Heath ${ }^{6}$ \\ ${ }^{1}$ Department of Geology and Geophysics, University of Wyoming, Laramie, Wyoming. \\ ${ }^{2}$ School of Energy Resources, University of Wyoming, Laramie, Wyoming. \\ ${ }^{3}$ Department of Geology and Geological Engineering and Hydrologic Sciences and Engineering Program, \\ Colorado School of Mines, Golden, Colorado. \\ ${ }^{4}$ Department of Chemical Engineering, University of Wyoming, Laramie, Wyoming. \\ ${ }^{5}$ Civil and Environmental Engineering, Colorado School of Mines, Golden, Colorado. \\ ${ }^{6}$ Chemical Sciences Division, Oak Ridge National Laboratory, Oak Ridge, Tennessee. \\ ${ }^{7}$ Geomechanics Department, Sandia National Laboratories, Albuquerque, New Mexico.
}

Received: December 24, 2015 Accepted in revised form: May 22, 2016

\begin{abstract}
Laboratory experiments evaluated two shale caprock formations, the Gothic Shale and Marine Tuscaloosa Formation, at conditions relevant to carbon dioxide $\left(\mathrm{CO}_{2}\right)$ sequestration. Both rocks were exposed to $\mathrm{CO}_{2^{-}}$ saturated brines at $160^{\circ} \mathrm{C}$ and $15 \mathrm{MPa}$ for $\sim 45$ days. Baseline experiments for both rocks were pressurized with argon to $15 \mathrm{MPa}$ for $\sim 35$ days. Varying concentrations of iron, aqueous silica, sulfate, and initial $\mathrm{pH}$ decreases coincide with enhanced carbonate and silicate dissolution due to reaction between $\mathrm{CO}_{2}$-saturated brine and shale. Saturation indices were calculated and activity diagrams were constructed to gain insights into sulfate, silicate, and carbonate mineral stabilities. Upon exposure to $\mathrm{CO}_{2}$-saturated brines, the Marine Tuscaloosa Formation appeared to be more reactive than the Gothic Shale. Evolution of aqueous geochemistry in the experiments is consistent with mineral precipitation and dissolution reactions that affect porosity. This study highlights the importance of tracking fluid chemistry to clarify downhole physicochemical responses to $\mathrm{CO}_{2}$ injection and subsequent changes in sealing capacity in $\mathrm{CO}_{2}$ storage and utilization projects.
\end{abstract}

Keywords: $\mathrm{CO}_{2}$ capture and storage; geochemical reactions; global-scale and regional-scale environmental impacts; inorganic geochemistry; thermodynamics and equilibrium

\section{Introduction}

G EOLOGIC CARBON CAPTURE utilization and storage (CCUS) is a promising approach for managing anthropogenic carbon dioxide $\left(\mathrm{CO}_{2}\right)$ emissions. Successful deployment of CCUS technologies relies on the presence of impermeable caprocks to facilitate structural trapping of injected $\mathrm{CO}_{2}$. Suitable caprocks include shales, whose finegrained, clay-rich nature make them excellent barriers to gas

*Corresponding author: Department of Geology and Geophysics, University of Wyoming, 1000 E. University Avenue, Laramie, WY 82071. Phone: (307) 766-6065; Fax: (307) 766-6679; E-mail: john.kaszuba@uwyo.edu

$\dagger$ Present address: Petroleum Engineering Department, China University of Petroleum-Beijing, Changping District, Beijing, China.

Present address: $\mathrm{CH} 2 \mathrm{M}$ Hill, Redding, CA.

${ }^{\S}$ Present address: Department of Physics, The University of Texas at El Paso, El Paso, TX. and fluid migration. Understanding how brine- $\mathrm{CO}_{2}$-rock reactions may alter shales is not only vital for predicting the long-term effectiveness of containment, but also provides insight into hydrocarbon extraction activities in which shale formations are produced as unconventional reservoir rocks. Economically favorable CCUS options often include a carbon utilization component, such as $\mathrm{CO}_{2}$-enhanced shale gas recovery (EGR) (Schaef et al., 2014). Utilization of supercritical $\mathrm{CO}_{2}$ as a "foam" hydraulic fracturing fluid component for tight (low permeability) oil and gas formations is also receiving increased attention as an alternative to the typical approach in which acidic aqueous fluids are used (Palmer and Sito, 2013; Barati and Liang, 2014).

Laboratory experiments provide valuable insight into geochemical and mineralogic changes induced by interactions among shale, brine, and $\mathrm{CO}_{2}$ (e.g., Kaszuba et al., 2003, 2005; Kohler et al., 2009; Alemu et al., 2011). Other experimental studies have addressed additional specific aspects of shale-brine- $\mathrm{CO}_{2}$ interactions of potential CCUS caprocks, 
the Gothic Shale and Marine Tuscaloosa Formation. Karamalidis et al. (2013) and Marcon and Kaszuba (2015) evaluated the potential for metal mobilization from the Marine Tuscaloosa Formation and from the contact of the Gothic Shale with an underlying carbonate reservoir, respectively, under conditions relevant to CCUS. Jung et al. (2013) and Zhong et al. (2014) examined the potential for organic and metal mobilization from the Gothic Shale in response to $\mathrm{CO}_{2}$ injection. In Part I of this two-part study, Mouzakis et al. (2016) investigated the impacts of geochemical reactions on nano- and micron-size porosity development under experimental conditions relevant to CCUS. Neutron scattering, electron microscopy, and other pore network characterization techniques were used to examine nanoscale changes on mineralogic aspects of porosity, pore connectivity, pore size distribution, and internal surface area of both the Gothic Shale and the Marine Tuscaloosa Formation. Changes to these pore network characteristics can significantly affect fluid saturation distribution, hydraulic conductivity, and wettability of caprock and reservoir rock which, in turn, may impact fluid containment and hydrocarbon production, respectively (Kaveh et al., 2014; Yao et al., 2014; Sarmadivaleh et al., 2015; Arif et al., 2016).

In this work, which is a continuation of the Mouzakis et al. (2016) study, we evaluate how aspects of the aqueous geochemistry of these same experiments evolve over the duration of the experiments. This information is synergistic with the mineralogic data determined in Part I of this study and constrains how porosity and pore connectivity, and ultimately geofluid storage and production, may change with time as a result of coupled physicochemical processes. As Song and Zhang (2013) highlight, understanding geochemically induced changes to pore networks is vital to accurately predicting the long-term behavior of caprock formations.

\section{Experimental Protocols}

\section{Batch experiments}

Samples of Gothic Shale or Marine Shale of the Tuscaloosa Group (henceforth referred to as the Marine Tuscaloosa) were reacted with formation specific brine and supercritical $\mathrm{CO}_{2}$ in hydrothermal experiments at $15 \mathrm{MPa}$ and $160^{\circ} \mathrm{C}$ as described by Mouzakis et al. (2016). Two control experiments were also conducted (in which argon was used to pressurize the reactors in lieu of $\mathrm{CO}_{2}$ ) to establish a baseline understanding of brine-rock interactions and provide a basis for evaluating $\mathrm{CO}_{2}$-brine-rock interactions. In this article, the brine-reacted experiments are referred to as Gothic-Brine and Marine-Brine, and the $\mathrm{CO}_{2}$-reacted experiments are referred to as Gothic- $\mathrm{CO}_{2}$ and Marine- $\mathrm{CO}_{2}$. The rocks are described in detail by Mouzakis et al. (2016) and Heath et al. (2011).

\section{Analytical methods}

Brine samples were periodically sampled and analyzed during the experiments. Extracted brine samples cooled and depressurized to ambient conditions within a few seconds and were subsequently processed. Retrograde reactions with minerals that may occur during a prolonged quench process were consequently avoided and solution composition was analyzed along a reaction pathway. Fluid samples were fil- tered using a Millipore $0.45 \mu \mathrm{m}$ filter. To prevent mineral precipitation, the samples for cation analysis were acidified to $\mathrm{pH} 2$ using trace metal grade nitric acid. Mineral precipitates were not observed in any of the brine samples. Major cation, anion, and minor constituent concentrations in the aqueous samples were determined by inductively coupled plasma optical emission spectroscopy, ion chromatography, and inductively coupled plasma mass spectrometry, respectively. Additionally, $\mathrm{pH}$ and total dissolved inorganic carbon were measured at "bench" conditions (degassed samples at $25^{\circ} \mathrm{C}$ and $0.1 \mathrm{MPa}$ ) using a carbon coulometer according to the methods of Chopping and Kaszuba (2012). In situ values of total dissolved inorganic carbon were determined by analyzing a sample of brine collected in a glass gas-tight syringe.

Upon termination, or "quench," the heated, insulating pressure vessel jackets were removed to quickly cool the experiments to minimize retrograde reactions of the fluids and rocks. After terminating each experiment, the remaining brine was filtered using a Millipore $0.45 \mu \mathrm{m}$ filter and analyzed according to the same protocols used for the other aqueous samples. The geochemistry of the quench sample and the aqueous sample collected immediately before the quench were compared to determine retrograde reactions that may have occurred while cooling and degassing the experiments.

\section{Geochemical models and calculations}

Geochemical calculations were performed to determine in situ $\mathrm{pH}$, aqueous species activities, and the saturation state of the brine with respect to different minerals. We used Geochemist's Workbench 10.0 (GWB), the b-dot ion association model, and the resident thermo.tdat database (Bethke and Yeakel, 2014) according to published methods (Chopping and Kaszuba, 2012; Lo Ré et al., 2014; Marcon and Kaszuba, 2015). We used thermo.tdat because it is internally consistent and handles aluminum speciation more adeptly than other available databases (Kaszuba et al., 2011). The ion size parameter for $\mathrm{CO}_{2}(\mathrm{aq})$ in this database was changed to -0.5 to correctly simulate the salting-out behavior of $\mathrm{CO}_{2}$ (Allen et al., 2005). Initial oxygen values were assumed to be negligible due to sparging of the brine (Mouzakis et al., 2016).

The $\mathrm{pH}$ at in situ pressure and temperature conditions was calculated for samples collected from the brine-reacted baseline experiments by speciating the fluid at $160^{\circ} \mathrm{C}$ using bench $\mathrm{pH}$, total dissolved inorganic carbon measured at the bench and at in situ conditions, and the aqueous geochemical data (Table 1). In situ $\mathrm{pH}$ was calculated for $\mathrm{CO}_{2}$-reacted experiments using the method of Newell et al. (2008) and total dissolved inorganic carbon calculated for in situ conditions using the equation-of-state of Duan et al. (2006). Hereafter, unless otherwise specified, in situ $\mathrm{pH}$ will be simply referred to as $\mathrm{pH}$. Total dissolved inorganic carbon was measured for samples withdrawn from the $\mathrm{CO}_{2}$-reacted experiments, but the results were inconsistent due to analytical difficulties and were therefore not used in the $\mathrm{pH}$ calculations. We were able to justifiably substitute equationof-state values for measured values because the brine was saturated with $\mathrm{CO}_{2}$ for the duration of the experiments.

\section{Results and Discussion}

Aqueous geochemical data from the four experiments are presented in Table 1 and selected data are shown in Figs. 1-5. 
Table 1. Aqueous Geochemistry for Four Shale+Brine $\pm \mathrm{CO}_{2}$ Experiments

\begin{tabular}{|c|c|c|c|c|c|c|c|c|c|c|c|c|c|}
\hline Time $(h)$ & $\mathrm{Na}$ & $K$ & $\mathrm{Ca}$ & $M g$ & $\mathrm{Fe}$ & $\begin{array}{c}\mathrm{SiO}_{2} \\
(a q)\end{array}$ & $\mathrm{Cl}$ & $\mathrm{SO}_{4}$ & $\sum_{\text {(bench) }} \mathrm{CO}_{2}$ & $\sum_{(\text {in situ) }} \mathrm{CO}_{2}$ & $\begin{array}{c}p H \\
\text { (bench) }\end{array}$ & $\begin{array}{c}p H \\
(\text { in situ })^{\mathrm{a}}\end{array}$ & $\begin{array}{l}\text { Charge } \\
\text { balance }\end{array}$ \\
\hline \multicolumn{14}{|c|}{ Water chemistry $\left(\mathrm{mmol} / \mathrm{kg}\right.$ ), brine-reacted Marine Tuscaloosa experiments (Marine-Brine), $160^{\circ} \mathrm{C}, 15 \mathrm{MPa}$} \\
\hline Initial Brine $^{\mathrm{b}}$ & $2,799.3$ & 67.8 & 324.5 & 6.0 & DL & 0.76 & $3,341.7$ & 2.5 & 0.3 & na & 7.1 & 6.5 & $2.6 \%$ \\
\hline 24 & & 6 & 27 & 5 & D. & 0.75 & 3,4 & 2.8 & 0 & 0.4 & & 5 & $\%$ \\
\hline 18 & & 73.0 & 336.2 & 6.5 & 0.62 & 1.20 & 3,4 & 2.8 & 0.2 & 1.0 & 5 & 5.2 & $-0.2 \%$ \\
\hline 354 & 7 & 64.0 & 300.1 & 6.0 & 0.36 & 1.24 & $3,441.6$ & 2.4 & $0.06^{\mathrm{c}}$ & 1.2 & 5.4 & $4.9^{\mathrm{c}}$ & $-3.6 \%$ \\
\hline 576 & 08.3 & 67.2 & 326.2 & 6.6 & 0.11 & 1.32 & $3,692.9$ & 2.2 & 0.2 & 0.9 & 5. & 5.3 & $-3.6 \%$ \\
\hline 698 & $2,603.0$ & 56.3 & 271.7 & 5.6 & DL & 1.15 & $3,590.0$ & 2.3 & 0.2 & 1.0 & 5.9 & 5.3 & $-5.6 \%$ \\
\hline 861 & $2,585.2$ & 66.9 & 320.1 & 6.5 & 0.45 & 1.42 & $3,631.1$ & 2.3 & 0.2 & 1.0 & 5.5 & 5.2 & $-4.7 \%$ \\
\hline Quer & $2,517.6$ & 60.8 & 315.2 & 6.3 & DL & 1.27 & $3,690.0$ & 2.3 & 0.2 & na & 5.6 & na & $-6.8 \%$ \\
\hline Uncertainty & \pm 34 & \pm 5.2 & \pm 5.1 & \pm 0.3 & \pm 0.02 & \pm 0.05 & \pm 50 & \pm 0.1 & $\pm 6 \%$ & na & \pm 0.1 & \pm 0.1 & na \\
\hline
\end{tabular}

Water chemistry $(\mathrm{mmol} / \mathrm{kg})$, supercritical $\mathrm{CO}_{2}$ and brine-reacted Marine Tuscaloosa experiments $\left(\mathrm{Marine}-\mathrm{CO}_{2}\right), 160^{\circ} \mathrm{C}$, $15 \mathrm{MPa}$

\begin{tabular}{|c|c|c|c|c|c|c|c|c|c|c|c|c|c|}
\hline Initial Brine ${ }^{\mathrm{b}}$ & $2,942.1$ & 75.4 & 336.1 & 7.1 & DL & 0.81 & $3,865.2$ & 2.6 & 0.1 & na & 7.2 & 5.5 & $-2.2 \%$ \\
\hline 27 & $2,701.8$ & 45.3 & 332.6 & 6.8 & 0.11 & 1.61 & $3,790.1$ & 3.0 & 7.2 & & 5.0 & 3.6 & $-5.1 \%$ \\
\hline 122 & $2,705.0$ & 68.9 & 335.6 & 7.1 & 0.17 & 1.85 & $3,834.8$ & 2.5 & 7.8 & e & 4.9 & 3.6 & $-5.2 \%$ \\
\hline 305 & $2,400.0$ & 61.6 & 276.6 & 6.2 & 0.41 & 1.73 & $2,767.0$ & 1.9 & 9.3 & $\mathrm{e}$ & 5.0 & 3.7 & $4.4 \%$ \\
\hline 481 & $2,646.3$ & 63.9 & 314.2 & 6.7 & 0.39 & 2.00 & $3,410.8$ & 1.9 & $10.7^{\mathrm{f}}$ & $\mathrm{e}$ & 5.1 & 3.8 & $-0.9 \%$ \\
\hline 694 & $2,531.9$ & 71.2 & 333.0 & 7.3 & 0.65 & 2.10 & $3,607.3$ & 1.6 & 12.2 & e & 5.0 & 3.8 & $-4.7 \%$ \\
\hline 1,006 & $2,528.1$ & 67.7 & 333.5 & 7.2 & 0.82 & 1.80 & $3,604.8$ & 1.8 & 0.8 & e & 5.2 & 3.4 & $-4.8 \%$ \\
\hline Quench $^{\mathrm{d}}$ at 1,009 & $2,552.7$ & 65.4 & 326.1 & 7.2 & 0.80 & 1.60 & $3,586.7$ & 2.0 & 14.5 & na & 5.1 & na & $-4.4 \%$ \\
\hline Uncertainty & \pm 34 & \pm 5.2 & \pm 5.1 & \pm 0.3 & \pm 0.02 & \pm 0.05 & \pm 50 & \pm 0.1 & $\pm 6 \%$ & na & \pm 0.1 & \pm 0.1 & na \\
\hline
\end{tabular}

Water chemistry $(\mathrm{mmol} / \mathrm{kg})$, brine-reacted Gothic shale experiments (Gothic-Brine), $160^{\circ} \mathrm{C}, 15 \mathrm{MPa}$

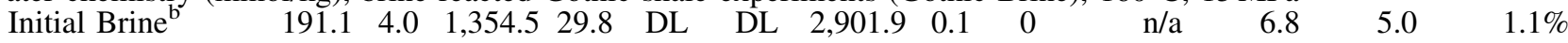

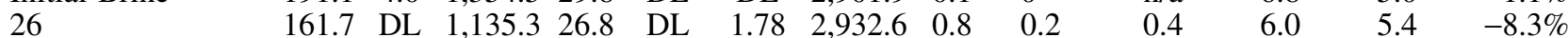

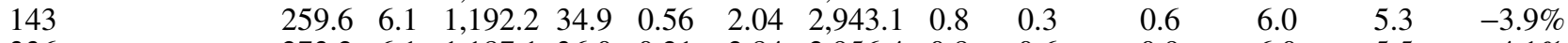

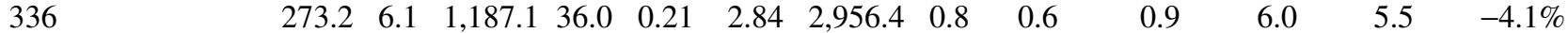

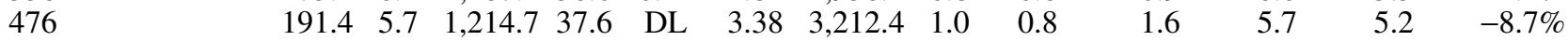

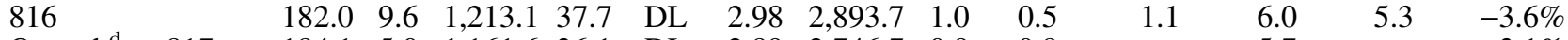

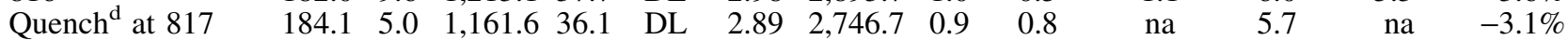

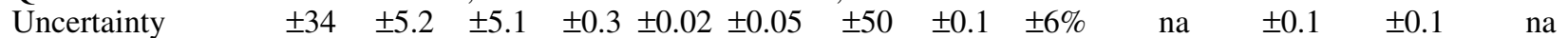

Water chemistry (mmol/kg), supercritical $\mathrm{CO}_{2}$ and brine-reacted Gothic shale experiments $\left(\mathrm{Gothic}^{\mathrm{C}} \mathrm{CO}_{2}\right), 160^{\circ} \mathrm{C}, 15 \mathrm{MPa}$

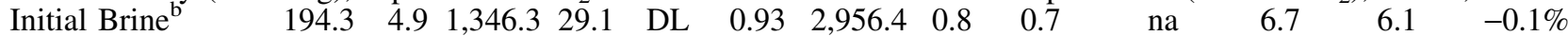

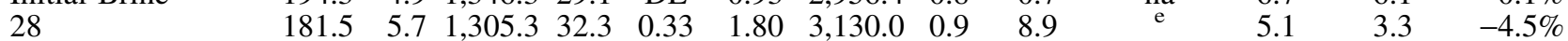

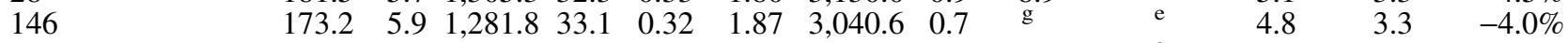

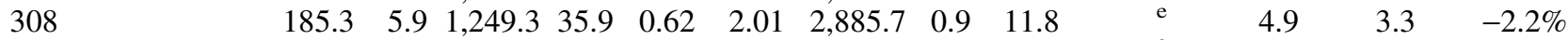

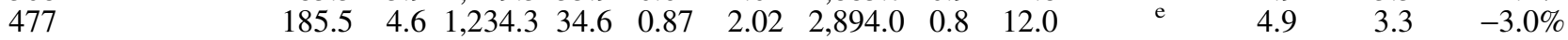

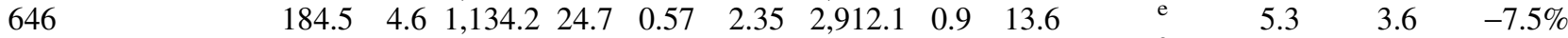

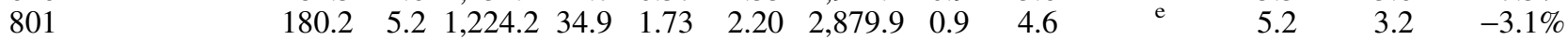

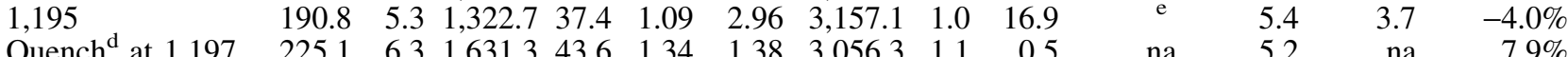

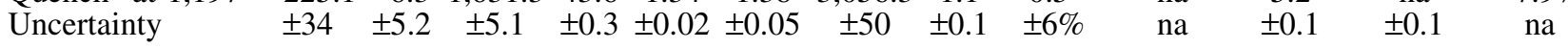

${ }^{\mathrm{a} C}$ Calculated value, see Experimental Protocols section for explanation of methods.

${ }^{\mathrm{b}}$ Composition of initial, unreacted brine.

${ }^{\mathrm{c}}$ Anomalously low dissolved inorganic carbon analysis contributes to lower in situ $\mathrm{pH}$.

${ }^{\mathrm{d}}$ Composition of brine after experiment is terminated.

${ }^{\mathrm{e}}$ Measured values were inconsistent and unreliable, values of $705.3 \mathrm{mmol} / \mathrm{kg}$ (Marine) and $656.9 \mathrm{mmol} / \mathrm{kg}$ (Gothic) were determined using the Duan et al. (2006) equation of state and used for in situ $\mathrm{pH}$ calculations, as explained in Experimental Protocols section.

${ }^{\mathrm{f}}$ Analysis not available, for calculation of in situ $\mathrm{pH}$ we assumed the median value of the preceding $(305 \mathrm{~h})$ and subsequent $(694 \mathrm{~h})$ samples.

${ }^{\mathrm{g}}$ Analysis not available, for calculation of in situ $\mathrm{pH}$ we assumed the same value as measured for sample at $308 \mathrm{~h}$.

$\mathrm{CO}_{2}$, carbon dioxide; DL, below detection limit; na, not applicable.

\section{Temporal evolution of $\mathrm{pH}$}

The $\mathrm{pH}$ of the Marine-Brine experiment decreased from a value of 5.8 ( $24 \mathrm{~h}$ sample) to $5.2(187 \mathrm{~h}$ sample) and, with the exception of the anomalous sample at $354 \mathrm{~h}$ (Table 1), remained relatively constant for the duration of the experiment (Fig. 1). In contrast, $\mathrm{pH}$ in the Gothic-Brine experiment and both $\mathrm{CO}_{2}$-reacted experiments remained relatively constant (Fig. 1). The $\mathrm{pH}$ values of the Marine- $\mathrm{CO}_{2}$ and Gothic- $\mathrm{CO}_{2}$ experiments were approximately $1.5-2 \mathrm{pH}$ units lower than those of the brine-reacted baseline experiments (Fig. 1), results consistent with other experimental studies of $\mathrm{CO}_{2}-$ water-rock interactions (Chopping and Kaszuba, 2012; Lo Ré et al., 2014; Marcon and Kaszuba, 2015). The lower pH of the $\mathrm{CO}_{2}$-reacted experiments was caused by dissolution of supercritical $\mathrm{CO}_{2}$ into the brine and subsequent generation of carbonic acid. The $\mathrm{pH}$ in these two experiments remained relatively constant $(\sim 3.5)$ for the duration of each experiment. 


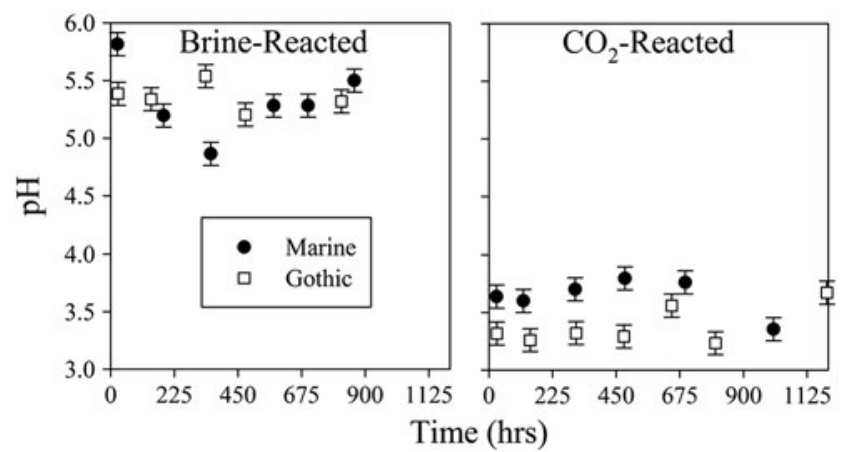

FIG. 1. Values of in situ $\mathrm{pH}$ versus time for brine-reacted (left) and $\mathrm{CO}_{2}$-reacted (right) experiments of Marine Tuscaloosa (filled circle) and Gothic Shale (open squares) at $160^{\circ} \mathrm{C}$ and $15 \mathrm{MPa}$. The $\mathrm{pH}$ of $\mathrm{CO}_{2}$-reacted experiments evolves at approximately two $\mathrm{pH}$ units less than the $\mathrm{pH}$ of the brine-reacted experiments due to the dissolution of supercritical $\mathrm{CO}_{2}$ and formation of carbonic acid in brine. Analytical uncertainties are depicted for each sample. $\mathrm{CO}_{2}$, carbon dioxide.

This uniform $\mathrm{pH}$ is due to the supercritical $\mathrm{CO}_{2}$ headspace, which functions as an infinite reservoir of $\mathrm{CO}_{2}$ that controls the carbonic acid equilibria.

\section{Marine Tuscaloosa experiments}

Concentrations of magnesium and calcium remained relatively constant at $\sim 6.5$ and $\sim 315 \mathrm{mmol} / \mathrm{kg}$, respectively, for the duration of both the Marine- $\mathrm{CO}_{2}$ and Marine-Brine experiments (Fig. 2). In contrast, concentrations of dissolved silica, iron, and sulfate exhibited important differences between the two experiments. Relative to the brine chemistry

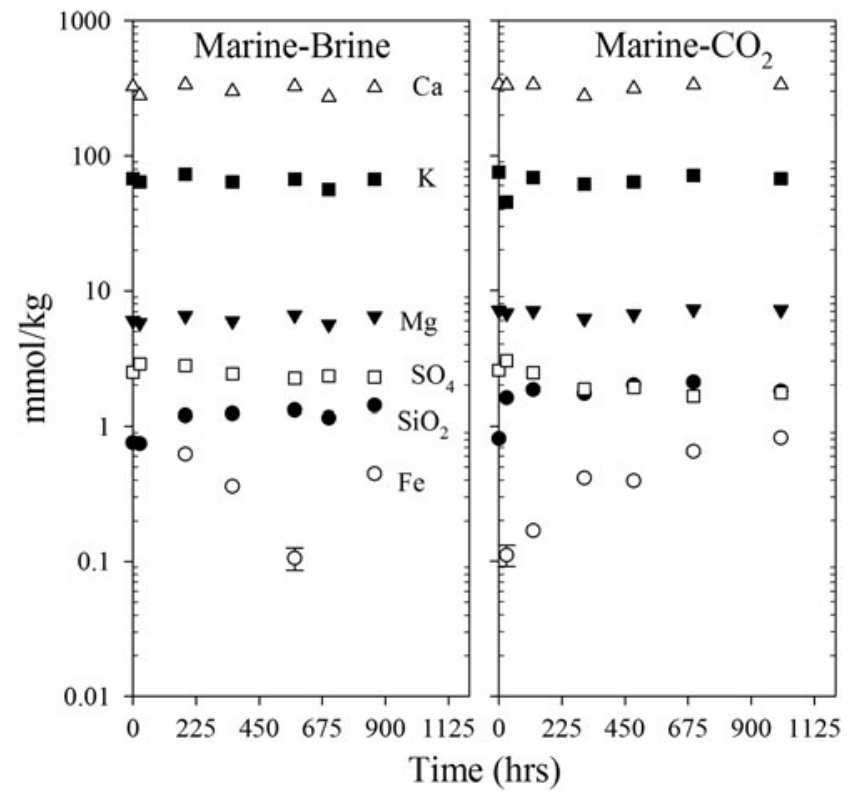

FIG. 2. Aqueous geochemistry versus time for select analytes in brine-reacted (left) and $\mathrm{CO}_{2}$-reacted (right) Marine Tuscaloosa experiments. For clarity, only error bars that are larger than the size of the symbol are included.

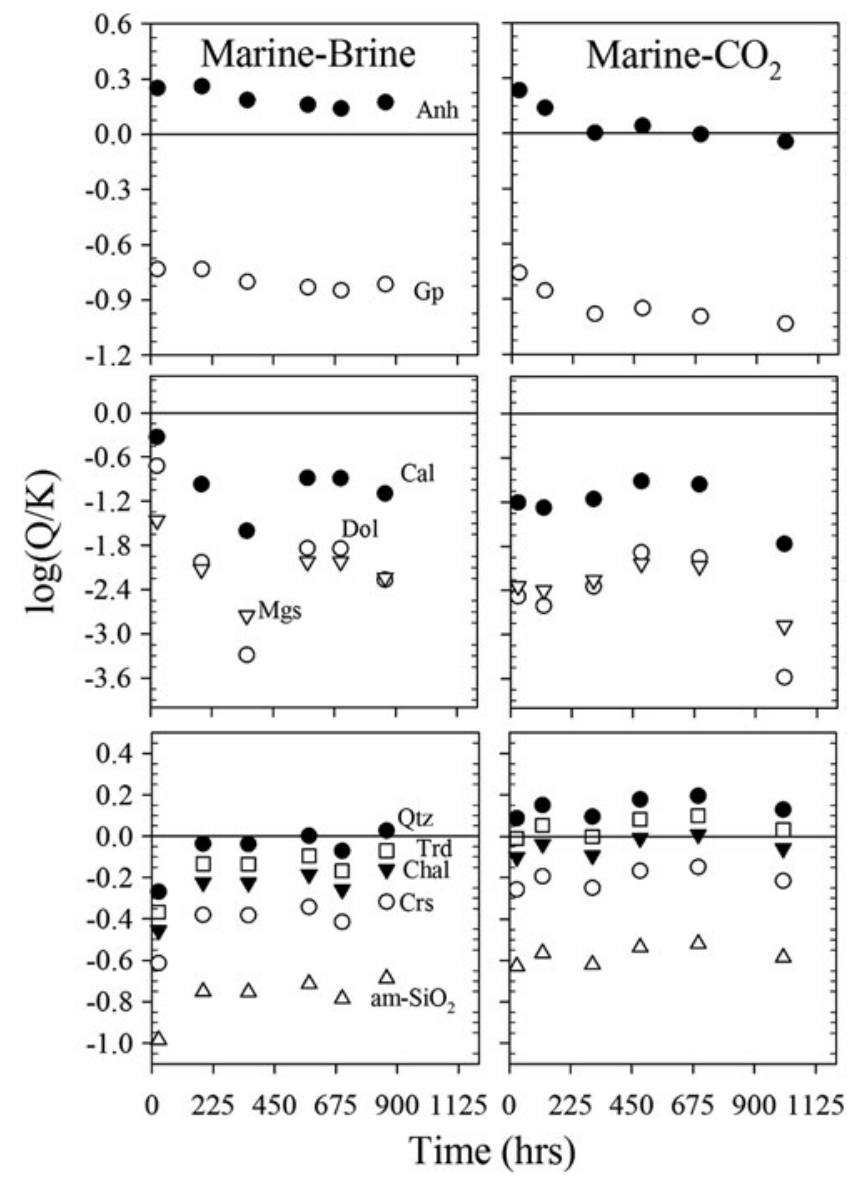

FIG. 3. Saturation index versus time for select sulfate (top), carbonate (middle), and silica (bottom) minerals in brine-reacted (left) and $\mathrm{CO}_{2}$-reacted (right) experiments of the Marine Tuscaloosa. The horizontal line at $\log (\mathrm{Q} / \mathrm{K})=0$ indicates the brine is saturated with respect to the plotted minerals. Data that plot above the line indicate the brine is supersaturated with respect to the mineral whereas data that plot below the line indicate the brine is undersaturated with respect to the mineral. Mineral abbreviations and symbols: am-SiO ${ }_{2}$, amorphous silica (open triangles); Anh, anhydrite (closed circles); Cal, calcite (closed circles); Chal, chalcedony (closed triangles); Crs, cristobalite (open circles); Dol, dolomite (open circles); Gp, gypsum (open circles); Mgs, magnesite (open triangles); Qtz, quartz (closed circles); Trd, tridymite (open squares).

of the Marine-Brine experiment and the initial $(0 \mathrm{~h})$ brine composition of the Marine- $\mathrm{CO}_{2}$ experiment, iron concentrations in the brine steadily increased throughout the duration of the $1,006 \mathrm{~h}$ Marine- $\mathrm{CO}_{2}$ experiment (Table 1 and Fig. 2). Similar behavior was observed for silica, except the increase was an initial spike in concentration after $24 \mathrm{~h}$ of reaction, followed by a gradual attainment of a steady state concentration that was elevated by $\sim 0.6 \mathrm{mmol} / \mathrm{kg}$ relative to that of the Marine-Brine experiment. Elevated aqueous silica is consistent with silicate dissolution and scanning electron microscopy imaging of reacted Marine- $\mathrm{CO}_{2}$ samples reported by Mouzakis et al. (2016), which revealed that new pores developed on the sheet silicates. Lastly, both experiments exhibited initial spikes of aqueous sulfate concentrations after $\sim 24 \mathrm{~h}$, after which the concentrations 


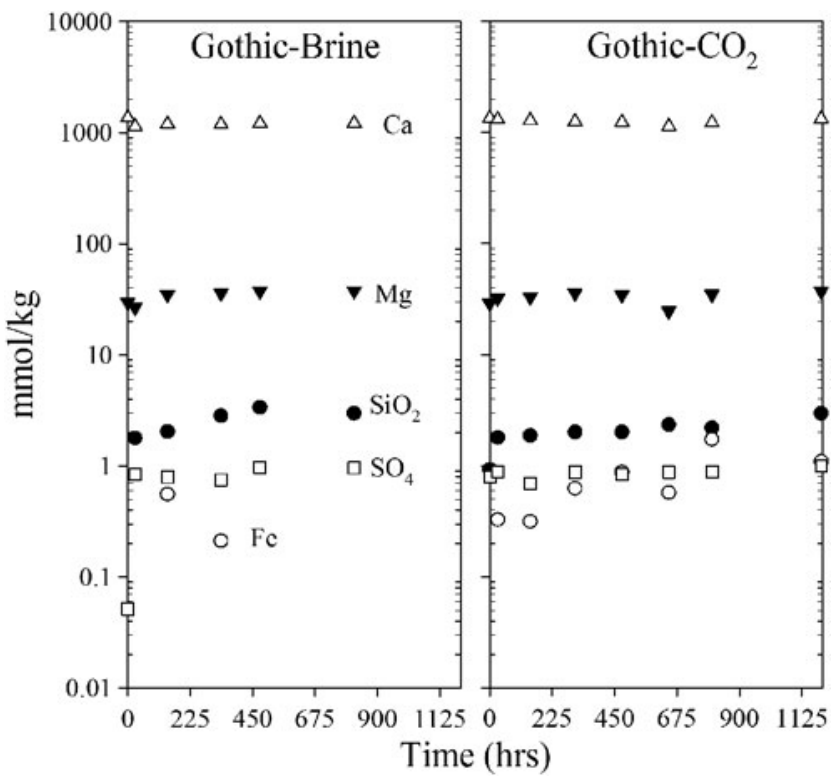

FIG. 4. Aqueous geochemistry versus time for select analytes in brine-reacted (left) and $\mathrm{CO}_{2}$-reacted (right) Gothic shale experiments. For clarity, only error bars that are larger than the size of the symbol are included and potassium is not shown due to the large uncertainties relative to the concentrations (Table 1).

gradually decreased to or below initial the sulfate concentrations of $\sim 2.5 \mathrm{mmol} / \mathrm{kg}$ (Fig. 2). The magnitude of the decrease was twice as much for the Marine- $\mathrm{CO}_{2}$ experiment than that of the Marine-Brine. As described in the following paragraphs, these aqueous trends are consistent with removal from, and addition to, the brine by mineral precipitation and dissolution, respectively.

Saturation state calculations (Fig. 3) provide insight into mineral stability at experimental conditions. Throughout the duration of both experiments, the brine was saturated with respect to anhydrite and undersaturated with respect to gypsum. The Marine-Brine fluid was always supersaturated with respect to anhydrite, while the Marine- $\mathrm{CO}_{2}$ brine started supersaturated and became saturated after $300 \mathrm{~h}$. These saturation states are consistent with neoformed calcium sulfate precipitates observed by Mouzakis et al. (2016) and indicate that these precipitates are likely anhydrite. Those workers observed a greater extent of calcium sulfate precipitation in the Marine- $\mathrm{CO}_{2}$ than the Marine-Brine experiment. Trends in anhydrite saturation indices, decreasing aqueous sulfate concentrations, and the relative abundance of precipitates observed are consistent with enhanced anhydrite precipitation in Marine- $\mathrm{CO}_{2}$ compared to Marine-Brine experiments.

The brine was undersaturated with respect to the carbonate minerals calcite, dolomite, and magnesite for both Marine$\mathrm{CO}_{2}$ and Marine-Brine experiments (Fig. 3). The saturation indices display no coherent trend, and continuous carbonate undersaturation is the only commonality for both experiments. On average, brine in the Marine- $\mathrm{CO}_{2}$ experiment is more undersaturated with respect to carbonates than that of the Marine-Brine baseline experiment. This relationship is consistent with the decreased $\mathrm{pH}$ conditions induced by

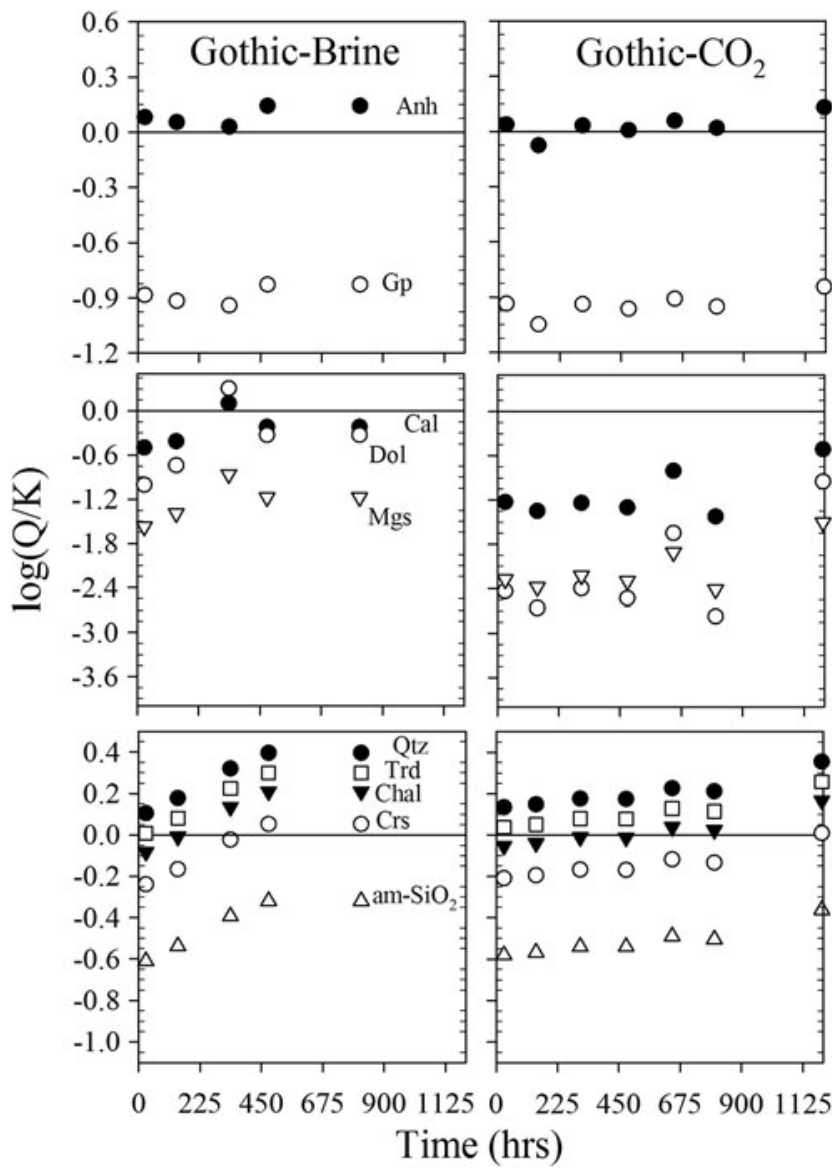

FIG. 5. Saturation index versus time for select sulfate (top), carbonate (middle), and silica (bottom) minerals in brine-reacted (left) and $\mathrm{CO}_{2}$-reacted (right) Gothic shale experiments. The horizontal $\operatorname{line}$ at $\log (\mathrm{Q} / \mathrm{K})=0$ indicates the brine is saturated with respect to the plotted minerals. Data that plot above the line indicate the brine is supersaturated with respect to the mineral whereas data that plot below the line indicate the brine is undersaturated with respect to the mineral.

dissolution of $\mathrm{CO}_{2}$ into brine. Elevated iron concentrations in Marine- $\mathrm{CO}_{2}$ are likely due to enhanced dissolution of ironcontaining carbonates. While the iron could, in principle, also be derived from another mineral such as chlorite or pyrite, carbonate dissolution is the more likely source due to the elevated dissolution kinetics of carbonates at lower $\mathrm{pH}$ (Palandri and Kharaka, 2004; Kaszuba et al., 2013). Additionally, the chlorite in the sandstone reservoir below the Marine Tuscaloosa was found to be a nonreactive armoring component (Lu et al., 2012). Although oxidative pyrite dissolution has been observed in experiments that react rocks with $\mathrm{CO}_{2}$ and an oxygen additive (Jung et al., 2013), imaging by Mouzakis et al. (2016) did not reveal evidence of pyrite dissolution, likely due to the argon sparging of the initial brine. Due to the high concentrations of calcium in the initial brines and the high water to rock ratio of $\sim 54: 1$ (Mouzakis et al., 2016), contributions from magnesium- and calciumreleasing carbonate dissolution and juxtaposed calciumconsuming anhydrite precipitation reactions were not evident in the near-constant aqueous calcium concentration trends. 
Lastly, the elevated silica concentrations in the Marine$\mathrm{CO}_{2}$ brine correspond to saturation indices greater than zero for quartz and other silica polymorphs, and are consistent with silicate mineral dissolution. Compared to the MarineBrine results, the Marine- $\mathrm{CO}_{2}$ saturation indices for quartz, chalcedony, cristobalite and tridymite, and amorphous silica experienced greater increases (Fig. 3). Saturation indices for opal proxies, cristobalite and tridymite, were calculated to provide insight into a broad range of cryptocrystalline and/or amorphous silica behavior. Silica supersaturation and inhibition of quartz precipitation in acidic, $\mathrm{CO}_{2}$-charged fluids is consistent with previous experimental work (Kaszuba et al., 2005) and field observations at $\mathrm{CO}_{2}$ injection sites (Kaszuba and Janecky, 2009).

\section{Gothic Shale experiments}

In contrast with the Marine Tuscaloosa experiments, the brine chemistry of both Gothic Shale experiments exhibited similar behaviors in regards to aqueous sulfate concentrations and corresponding calcium sulfate saturation indices (Figs. 4 and 5). Both brines were saturated with respect to anhydrite and undersaturated with respect to gypsum. Silicate mineral dissolution did not appear to be enhanced in the Gothic- $\mathrm{CO}_{2}$ experiment relative to the Gothic-Brine experiment. In the Gothic-Brine experiment, aqueous silica concentrations increased to a maximum of $3.4 \mathrm{mmol} / \mathrm{kg}$ after only $476 \mathrm{~h}$. In contrast, it took $1,195 \mathrm{~h}$ of steadily increasing silica levels to reach $3.0 \mathrm{mmol} / \mathrm{kg}$ in the Gothic- $\mathrm{CO}_{2}$ experiment. Silica concentrations in the Gothic-Brine experiment appear to have been approaching steady state values, whereas silica concentrations in the Gothic- $\mathrm{CO}_{2}$ experiment continued to increase throughout the duration of the experiment. It is possible that silica concentrations may have continued to increase in the Gothic- $\mathrm{CO}_{2}$ experiment given longer reaction timescales.

Iron concentrations in the Gothic- $\mathrm{CO}_{2}$ experiment steadily increased throughout the duration of the 1,195-h experiment; no iron was measured in the initial $(0 \mathrm{~h})$ brine (Table 1 and Fig. 4). In contrast, aqueous iron was detected in only two samples withdrawn from the Gothic-Brine experiment (143 and $336 \mathrm{~h}$ ). These relationships have been observed in other experimental studies of $\mathrm{CO}_{2}$-water-rock interactions in carbonate-bearing rocks (Chopping and Kaszuba, 2012) and are consistent with dissolution of iron-bearing carbonate minerals in $\mathrm{CO}_{2}$-charged brine relative to the control brine experiment. Despite fluctuations in the saturation states (Fig. 5), it is clear that the $\mathrm{CO}_{2}$-charged brine was more undersaturated with respect to the carbonate minerals, which indicates enhanced carbonate dissolution in the Gothic- $\mathrm{CO}_{2}$ experiment relative to the Gothic-Brine experiment.

\section{Mineral precipitation}

Understanding secondary phase formation is important, as it has the potential to alter caprock wetting properties and subsequent effectiveness as a seal (Chiquet et al., 2007). To provide insight into potential mineral transformations, activity diagrams were developed to investigate mineral stability relationships in the system $\mathrm{Na}_{2} \mathrm{O}-\mathrm{Al}_{2} \mathrm{O}_{3}-\mathrm{SiO}_{2}-\mathrm{H}_{2} \mathrm{O}$. Other than the 24-h sample (Table 1), brine in the Marine-Brine experiment is in equilibrium with albite and kaolinite and the silica activity is controlled by the solubility of quartz (Fig. 6).

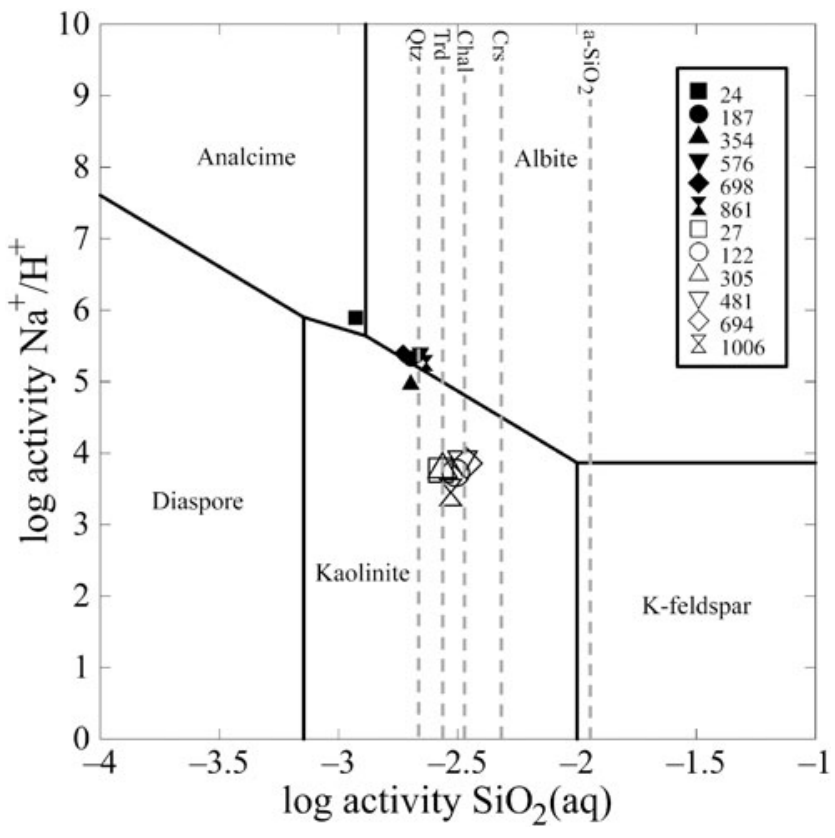

FIG. 6. Mineral stability relationships for the system $\mathrm{Na}_{2} \mathrm{O}-\mathrm{Al}_{2} \mathrm{O}_{3}-\mathrm{SiO}_{2}-\mathrm{H}_{2} \mathrm{O}$ constructed for Marine Tuscaloosa experiments at $160^{\circ} \mathrm{C}$ and $15 \mathrm{MPa}$. The dashed vertical lines represent saturation with respect to quartz, chalcedony, proxies for opal (cristobalite and tridymite), and amorphous silica. The chemistry of the $\mathrm{CO}_{2}$-saturated brine (Table 1) was used to construct the diagram. Activities of aqueous species for individual samples are plotted on the diagram; brine-reacted experiments are denoted by filled symbols and $\mathrm{CO}_{2}$-reacted experiments in open symbols. Numbers in the inset legend indicate the hours of reaction time in the experiment (Table 1).

These relationships are consistent with the mineralogy of the Marine Tuscaloosa shale (Heath et al., 2011; Mouzakis et al., 2016). In contrast, brine samples from the Marine- $\mathrm{CO}_{2}$ experiment cluster in the middle of the kaolinite stability field, indicating the potential for albite dissolution and kaolinite precipitation when the shale-brine system is exposed to supercritical $\mathrm{CO}_{2}$ (Fig. 6). Additionally, the silica activity shifts to being controlled by the solubility of chalcedony and tridymite (opal proxy) instead of quartz. The predicted mineral stabilities for the Gothic-Brine experiment are consistent with the mineralogy of the Gothic Shale (Heath et al., 2011; Mouzakis et al., 2016). The fluid chemistries of the Gothic-Brine experiment indicate that albite and muscovite (illite proxy) are in equilibrium, whereas albite dissolution and muscovite precipitation are favored in the Gothic- $\mathrm{CO}_{2}$ experiment (Fig. 7). In both Gothic Shale experiments, the controls on silica activity shift from tridymite to chalcedony and finally to cristobalite solubility (Figs. 5 and 7). The solubility of amorphous silica could ultimately control silica activity in a longer-duration Gothic$\mathrm{CO}_{2}$ experiment.

Potential for secondary mineral formation has implications for the evolution of porosity and permeability in shale formations. Precipitation in pores and pore throats and/or mobilization of neoformed precipitates (fines migration) derived from silicate mineral alteration and from silica-laden waters could potentially decrease the permeability of caprocks, which would be beneficial for carbon storage. In the 


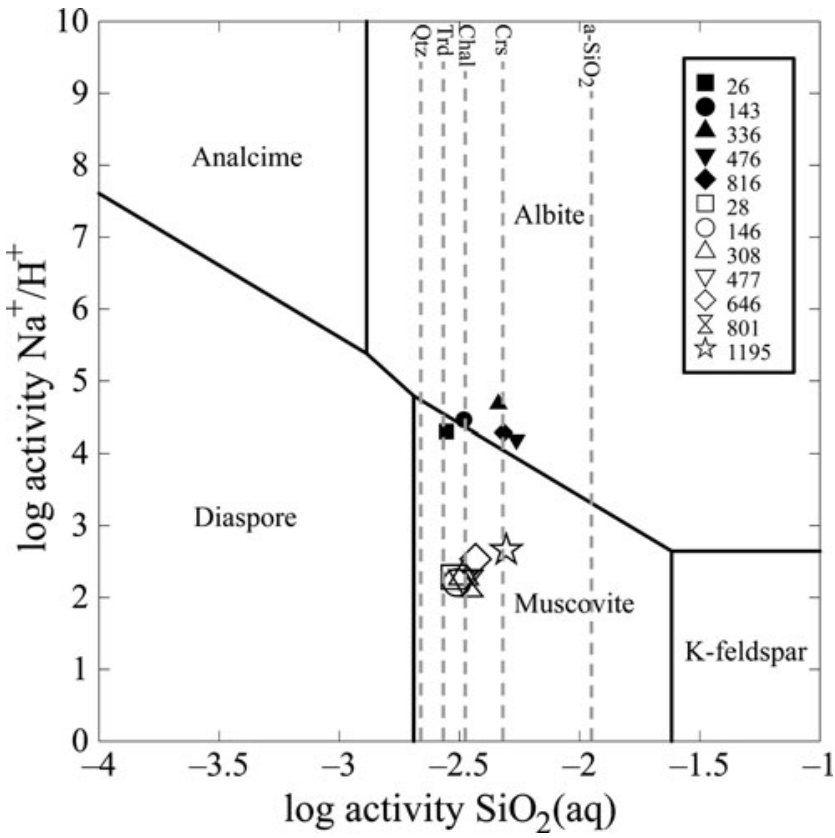

FIG. 7. Mineral stability relationships for the system $\mathrm{Na}_{2} \mathrm{O}$ $\mathrm{Al}_{2} \mathrm{O}_{3}-\mathrm{SiO}_{2}-\mathrm{H}_{2} \mathrm{O}$ constructed for Gothic experiments at $160^{\circ} \mathrm{C}$ and $15 \mathrm{MPa}$. The dashed vertical lines represent saturation with respect to quartz, chalcedony, proxies for opal (cristobalite and tridymite), and amorphous silica. The chemistry of the $\mathrm{CO}_{2}$-saturated brine (Table 1) was used to construct the diagram. Activities of aqueous species for individual samples are plotted on the diagram; brine-reacted experiments are denoted by filled symbols and $\mathrm{CO}_{2}$-reacted experiments in open symbols. Numbers in the inset legend indicate the hours of reaction time in the experiment (Table 1).

context of hydrocarbon production in tight formations, these processes have the potential to negatively impact injectivity and reservoir transmissivity.

Mouzakis et al. (2016) reported newly formed, possibly sodium-bearing, aluminosilicate precipitates in reacted rock samples recovered from both brine-reacted experiments but not the $\mathrm{CO}_{2}$-reacted experiments. These minerals may be sodium-zeolites, potentially analcime, minerals that have not been identified in either the unreacted Gothic Shale or the unreacted Marine Tuscaloosa. Precipitation of analcime is consistent with the aqueous geochemistry of the 24-h sample of the Marine-Brine experiment (Fig. 6) and with temporal trends of the aqueous geochemistry of both brine-reacted experiments (Figs. 6 and 7). Other experimental brine+rock \pm $\mathrm{CO}_{2}$ studies observed analcime precipitation only in brinereacted experiments, as the high silica concentrations and low $\mathrm{pH}$ of $\mathrm{CO}_{2}$-saturated brine are not conducive to analcime stability (Alemu et al., 2011; Lo Ré et al., 2014). While analcime was observed in some $\mathrm{CO}_{2}$-reacted experiments (Kaszuba et al., 2003, 2005), its formation in those studies is likely due to much higher initial concentrations of sodium in the brine, which promotes analcime stability.

\section{Comparative physicochemical reactivity}

Differences in the evolution of the aqueous geochemistry in the experiments suggests that the Marine Tuscaloosa was more reactive than the Gothic Shale after exposure to $\mathrm{CO}_{2}$ - saturated brine, which is consistent with the results of Mouzakis et al. (2016). Mobilization and scavenging of aqueous constituents by dissolving and precipitating minerals was pronounced in the Marine- $\mathrm{CO}_{2}$ experiment, while differences in aqueous geochemistry between the Gothic-Brine and Gothic- $\mathrm{CO}_{2}$ experiments were minor. The evolution of the aqueous geochemistry in these experiments is consistent with mineralogic and petrophysical changes described by Mouzakis et al. (2016), who observed relatively limited differences between pore network features of Gothic-Brine and Gothic- $\mathrm{CO}_{2}$ samples. However, the specific surface area, total porosity, and unconnected porosity increased in the Marine- $\mathrm{CO}_{2}$ sample compared to unreacted Marine Tuscaloosa and Marine-Brine samples (Mouzakis et al., 2016). The agreement between the rock- and fluid-focused studies emphasizes the importance of aqueous geochemistry as an effective tracer of in situ processes and highlights the continued value of experimentally derived geochemical data for clarifying coupled physicochemical subsurface processes.

\section{Conclusions}

This study utilized experimentally derived aqueous geochemistry to evaluate the effects of $\mathrm{CO}_{2}$ on brine-shale interactions for two distinct and representative CCUS caprock samples. Mineral stabilities, reaction paths, and extent of transformation were investigated. Evidence of caprock alteration includes release of iron from carbonate dissolution, supersaturation of brine with respect to quartz from silicate mineral dissolution, and precipitation of anhydrite. Differences in geochemical evolution of brine reacting with caprocks highlight the variable susceptibility of shales to reaction with $\mathrm{CO}_{2}$-saturated brines. Distinctive geochemical signatures that developed are consistent with mineral precipitation and pore-developing dissolution of the shales (Mouzakis et al., 2016). Coupling aqueous geochemistry with mineralogic data is vital for constraining parameters that are used in reactive transport models to predict the fate and transport of $\mathrm{CO}_{2}$ in the subsurface (Gaus et al., 2005; Xu et al., 2005).

We recommend that future work evaluate three additional aspects of shale reactivity. First, workers should investigate how fluid-rock ratios impact reactions, as the ratios may vary spatially and temporally in these systems, and the resultant data would be useful for parameterizing reservoir models. Secondly, reactions involving both minerals and organic matter, such as ion exchange, adsorption, and intercalation, do not conform to the simplified framework of mineral dissolution and precipitation. These reactions may obscure predicted aqueous trends and complicate interpretation of experimental data; therefore, these interactions need to be evaluated. Lastly, the potential for mineral transformations induced by interactions between water-bearing supercritical $\mathrm{CO}_{2}$ and shale (McGrail et al., 2009; Loring et al., 2012; Schaef et al., 2015) requires evaluation.

\section{Acknowledgments}

Q.R.S.M. acknowledges support from the University of Wyoming School of Energy Resources and a Center for Advanced Energy Studies Graduate Assistantship award. Q.R.S.M. also acknowledges support from the U.S. Department of Energy, Office of Science, Office of Workforce 
Development for Teachers and Scientists, Office of Science Graduate Student Research (SCGSR) program. The SCGSR program is administered by the Oak Ridge Institute for Science and Education for the DOE under contract number DEAC05-06OR23100. The authors acknowledge support from an EPA Star Grant R834387 to J.M., R.J. Maxwell, A.K.N.-S., and J.K., and by a United States Department of Energy Grant DE-FE0000730 to J.M. and A.K.N.-S. J.K.'s work was also supported by the University of Wyoming School of Energy Resources. G.R. was supported as part of the Nanoscale Control of Geologic $\mathrm{CO}_{2}$ Center, an Energy Frontier Research Center funded by the United States Department of Energy Office of Science and Office of Basic Energy Science. We acknowledge The Laboratory for Environmental and Geological Studies at the University of Colorado, particularly Fredrick G. Luiszer, for aqueous analyses. The authors also are grateful for the feedback of three anonymous reviewers, whose suggestions helped strengthen the article.

\section{Author Disclosure Statement}

No competing financial interests exist.

\section{References}

Alemu, B.L., Aagaard, P., Munz, I.A., and Skurtveit, E. (2011). Caprock interaction with $\mathrm{CO}_{2}$ : A laboratory study of reactivity of shale with supercritical $\mathrm{CO}_{2}$ and brine. Appl. Geochem. 26, 1975.

Allen, D.E., Strazisar, B.R., Soong, Y., and Hedges, S.W. (2005). Modeling carbon dioxide sequestration in saline aquifers: Significance of elevated pressures and salinities. Fuel Process. Technol. 86, 1569.

Arif, M., Al-Yaseri, A.Z., Barifcani, A., Lebedev, M., and Iglauer, S. (2016). Impact of pressure and temperature on $\mathrm{CO}_{2}$-brine-mica contact angles and $\mathrm{CO}_{2}$-brine interfacial tension: Implications for carbon geo-sequestration. J. Colloid Interface Sci. 462, 208.

Barati, R., and Liang, J.-T. (2014). A review of fracturing fluid systems used for hydraulic fracturing of oil and gas wells. J. Appl. Polym. Sci. 131, 40735.

Bethke, C.M., and Yeakel, S. (2014). The Geochemist's Workbench Release 10.0: Reaction Modeling Guide. Champaign, IL: Aqueous Solutions, LLC, p. 130.

Chiquet, P., Broseta, D., and Thibeau, S. (2007). Wettability alteration of caprock minerals by carbon dioxide. Geofluids 7 , 112.

Chopping, C., and Kaszuba, J.P. (2012). Supercritical carbon dioxide-brine-rock reactions in the Madison Limestone of Southwest Wyoming: An experimental investigation of a sulfur-rich natural carbon dioxide reservoir. Chem. Geol. 322, 223.

Duan, Z.H., Sun, R., Zhu, C., and Chou, I.M. (2006). An improved model for the calculation of $\mathrm{CO}_{2}$ solubility in aqueous solutions containing $\mathrm{Na}^{+}, \mathrm{K}^{+}, \mathrm{Ca}^{2+}, \mathrm{Mg}^{2+}, \mathrm{Cl}^{-}$, and $\mathrm{SO}_{4}{ }^{2-}$. Mar. Chem. 98, 131.

Gaus, I., Azaroual, M., and Czernichowski-Lauriol, I. (2005). Reactive transport modelling of the impact of $\mathrm{CO}_{2}$ injection on the clayey cap rock at Sleipner (North Sea). Chem. Geol. 217, 319.

Heath, J.E., Dewers, T.A., McPherson, B.J.O.L., Petrusak, R., Chidsey, T.C., Jr., Rinehart, A.J., and Mozley, P.S. (2011). Pore networks in continental and marine mudstones: Char- acteristics and controls on sealing behavior. Geosphere 7, 429.

Jung, H.B., Um, W., and Cantrell, K.J. (2013). Effect of oxygen co-injected with carbon dioxide on Gothic shale caprock$\mathrm{CO}_{2}$-brine interaction during geologic carbon sequestration. Chem. Geol. 354, 1.

Karamalidis, A.K., Torres, S.G., Hakala, J.A., Shao, H., Cantrell, K.J., and Carroll, S. (2013). Trace metal source terms in carbon sequestration environments. Environ. Sci. Technol. 47, 322.

Kaszuba, J., Yardley, B., and Andreani, M. (2013). Experimental perspectives of mineral dissolution and precipitation due to carbon dioxide-water-rock interactions. In D.J. DePaolo, D.R. Cole, A. Navrotsky, and I.C. Bourg, Eds., Geochemistry of Geologic $\mathrm{CO}_{2}$ Sequestration. Chantilly, VA: The Mineralogical Society of America, p. 153.

Kaszuba, J.P., and Janecky, D.R. (2009). Geochemical impacts of sequestering carbon dioxide in brine formations. In B. McPherson and E. Sundquist, Eds., Carbon Sequestration and Its Role in the Global Carbon Cycle. Washington, DC: American Geophysical Union, p. 239.

Kaszuba, J.P., Janecky, D.R., and Snow, M.G. (2003). Carbon dioxide reaction processes in a model brine aquifer at $200^{\circ} \mathrm{C}$ and 200 bars: Implications for geologic sequestration of carbon. Appl. Geochem. 18, 1065.

Kaszuba, J.P., Janecky, D.R., and Snow, M.G. (2005). Experimental evaluation of mixed fluid reactions between supercritical carbon dioxide and $\mathrm{NaCl}$ brine: Relevance to the integrity of a geologic carbon repository. Chem. Geol. 217, 277.

Kaszuba, J.P., Viswanathan, H.S., and Carey, J.W. (2011). Relative stability and significance of dawsonite and aluminum minerals in geologic carbon sequestration. Geophys. Res. Lett. 38, 404.

Kaveh, N.S., Rudolph, E.S.J., van Hemert, P., Rossen, W.R., and Wolf, K.H. (2014). Wettability evaluation of a $\mathrm{CO}_{2} /$ water/Bentheimer Sandstone system: Contact angle, dissolution, and bubble size. Energy Fuels 28, 4002.

Kohler, E., Parra, T., and Vidal, O. (2009). Clayey cap-rock behavior in $\mathrm{H}_{2} \mathrm{O}-\mathrm{CO}_{2}$ media at low pressure and temperature conditions: An experimental approach. Clays Clay Miner. 57, 616.

Lo Ré, C., Kaszuba, J.P., Moore, J.N., and McPherson, B.J. (2014). Fluid-rock interactions in $\mathrm{CO}_{2}$-saturated, granitehosted geothermal systems: Implications for natural and engineered systems from geochemical experiments and models. Geochim. Cosmochim. Acta 141, 160.

Loring, J.S., Schaef, H.T., Turcu, R.V.F., Thompson, C.J., Miller, Q.R.S., Martin, P.F., Hu, J., Hoyt, D.W., Qafoku, O., Ilton, E.S., et al. (2012). In situ molecular spectroscopic evidence for $\mathrm{CO}_{2}$ intercalation into montmorillonite in supercritical carbon dioxide. Langmuir 28, 7125.

Lu, J., Kharaka, Y.K., Thordsen, J.J., Horita, J., Karamalidis, A., Griffith, C., Hakala, J.A., Ambats, G., Cole, D.R., Phelps, T.J., et al. (2012). $\mathrm{CO}_{2}$-rock-brine interactions in Lower Tuscaloosa Formation at Cranfield $\mathrm{CO}_{2}$ sequestration site, Mississippi, USA. Chem. Geol. 291, 269.

Marcon, V., and Kaszuba, J.P. (2015). Carbon dioxide-brinerock interactions in a carbonate reservoir capped by shale: Experimental insights regarding the evolution of trace metals. Geochim. Cosmochim. Acta 168, 22.

McGrail, B.P., Schaef, H.T., Glezakou, V.A., Dang, L.X., and Owen, A.T. (2009). Water reactivity in the liquid and supercritical $\mathrm{CO}_{2}$ phase: Has half the story been neglected? Energy Procedia 1, 3415. 
Mouzakis, K., Navarre-Stitchler, A.K., Rother, G., Bañuelos, J.L., Wang, X., Kaszuba, J., Heath, J., Miller, Q.R.S., Alvarado, V., and McCray, J. Experimental study of porosity changes in shale caprocks exposed to $\mathrm{CO}_{2}$-saturated brine I: Evolution of mineralogy, pore connectivity, pore size distribution, and surface area. Environ. Eng. Sci. 33, 725.

Newell, D.L., Kaszuba, J.P., Viswanathan, H.S., Pawar, R.J., and Carpenter, T. (2008). Significance of carbonate buffers in natural waters reacting with supercritical $\mathrm{CO}_{2}$ : Implications for monitoring, measuring and verification (MMV) of geologic carbon sequestration. Geophys. Res. Lett. 35, 403.

Palandri, J.L., and Kharaka, Y.K. (2004). A Compilation of Rate Parameters of Water-Mineral Interaction Kinetics for Application to Geochemical Modeling. Menlo Park, CA: United States Geological Survey, p. 64.

Palmer, C., and Sito, Z. (2013). Nitrogen and carbon dioxide fracturing fluids for the stimulation of unconventional shale plays. AGH Drill. Oil Gas 30, 191.

Sarmadivaleh, M., Al-Yaseri, A.Z., and Iglauer, S. (2015). Influence of temperature and pressure on quartz-water- $\mathrm{CO}_{2}$ contact angle and $\mathrm{CO}_{2}$-water interfacial tension. J. Colloid Interface Sci. 441, 59.
Schaef, H.T., Davidson, C.L., Owen, A.T., Miller, Q.R.S., Loring, J.S., Thompson, C.J., Bacon, D.H., Glezakou, V.A., and McGrail, B.P. (2014). $\mathrm{CO}_{2}$ utilization and storage in shale gas reservoirs: Experimental results and economic impacts. Energy Procedia 63, 7844.

Schaef, H.T., Loring, J.S., Glezakou, V.-A., Miller, Q.R.S., Chen, J., Owen, A.T., Lee, M.-S., Ilton, E.S., Felmy, A.R., McGrail, B.P., et al. (2015). Competitive sorption of $\mathrm{CO}_{2}$ and $\mathrm{H}_{2} \mathrm{O}$ in 2:1 layer phyllosilicates. Geochimica Et Cosmochimica Acta 161, 248.

Song, J., and Zhang, D. (2013). Comprehensive review of caprock-sealing mechanisms for geologic carbon sequestration. Environ. Sci. Technol. 47, 9.

$\mathrm{Xu}, \mathrm{T}$., Apps, J.A., and Pruess, K. (2005). Mineral sequestration of carbon dioxide in a sandstone-shale system. Chem. Geol. 217, 295.

Yao, C.-W., Alvarado, J.L., Marsh, C.P., Jones, B.G., and Collins, M.K. (2014). Wetting behavior on hybrid surfaces with hydrophobic and hydrophilic properties. Appl. Surf. Sci. 290, 59.

Zhong, L., Cantrell, K., Mitroshkov, A., and Shewell, J. (2014). Mobilization and transport of organic compounds from reservoir rock and caprock in geological carbon sequestration sites. Environ. Earth Sci. 71, 4261. 